\title{
INVENTARISASI KUPU-KUPU RHOPALOCERA PADA DUA KAWASAN BERBEDA DI PROVINSI RIAU
}

\author{
Ennie Chahyadi ${ }^{1)}$, Dewi Indriyani Roslim ${ }^{2)}$, Sri Wahyuningsih ${ }^{3)}$ \\ 1,2,3 Jurusan Biologi, Universitas Riau \\ Email $^{l)}$ : chahyadi.ennie@gmail.com \\ Email ${ }^{2}$ : iinroslim@gmail.com \\ Email ${ }^{3)}$ :wahyuningsihsri31@gmail.com
}

\begin{abstract}
ABSTRAK : Kupu-kupu Rhopalocera merupakan organisme yang memiliki morfologi yang indah dan berperan penting di alam. Namun jenis kupu-kupu tersebut masih belum banyak diketahui khususnya di Provinsi Riau. Penelitian ini bertujuan untuk mengidentifikasi jenis kupu-kupu di berbagai daerah di Provinsi Riau. Metode yang digunakan adalah eksplorasi dengan menangkap kupu-kupu secara langsung menggunakan jaring serangga. Sampel tersebut kemudian diawetkan dalam bentuk insektarium. Kemudian diidentifikasi berdasarkan karakter kepala, dada, sayap dan perut. Hasil yang diperoleh sebanyak 47 jenis kupu-kupu dan 363 individu kupu-kupu. Ada sebanyak 18 spesies kupu-kupu yang sama dari kedua wilayah tersebut. Jenis dan individu kupu-kupu dari kedua wilayah tersebut didominasi oleh famili Nymphalidae.
\end{abstract}

\section{Kata Kunci : Kupu-kupu, Rhopalocera, Provinsi Riau}

ABSTRACT : Rhopalocera butterfly is an organism that has a beautiful morphology and an important role in nature. However, the types of butterflies are still not widely known, especially in Riau Province. The aim of this study was to identify the types of butterflies in different areas in Riau Province. The method used is exploration by directly catching butterflies using insect nets. The sample is then preserved in the form of an insectarium. Then identified based on the character of the head, thorax, wings and abdomen. The results obtained as many as 47 species and 363 individuals of butterflies. There are as many as 18 species of the same butterfly from the two regions. Types and individuals of butterflies from the two regions are dominated by the family Nymphalidae.

Keywords: Butterfly, Rhopalocera, Riau Province

1. PENDAHULUAN

Sub Ordo Rhopalocera yang termasuk ke dalamnya adalah serangga kupu-kupu, memiliki karakter morfologi yang khas dan sangat bervariasi. Ciri tersebut dapat dilihat dari karakter sisik yang beranekaragam pada corak warna, pola dan bentuk sayap (Peggie 2014). Sehingga karakter inilah yang menjadikan kupu-kupu sebagai salah satu hewan yang indah dan menjadi daya tarik suatu wilayah, termasuk di beberapa kawasan Provinsi Riau. Selain itu, peran dari kupu-kupu di alam juga tidak kalah menarik dari pesona morfologinya. Kupu-kupu dapat menjadi bioindikator lingkungan, polinator dan juga memiliki nilai serta manfaat di bidang estetika, budaya, ekonomi dan penelitian (Rizal 2007; Raja 2012; Subahar \& Yuliana 2012; Peggie 2014).

Keberadaan kupu-kupu banyak ditemukan di beberapa kawasan di Provinsi Riau. Namun belum banyak informasi mengenai jenis dan juga karakter kupu-kupu apa saja yang ada di kawasan tersebut. Bagaimana hubungan kekerabatan antara kupu-kupu yang berada di kawasan satu dengan yang lainnya, juga belum pernah diteliti. Keberadaan jenis kupu-kupu dipengaruhi oleh vegetasi di 
habitatnya. Selain itu, faktor lingkungan juga mempengaruhi keberagaman jenis kupu-kupu seperti suhu udara dan pencahayaan (Putri 2014; Lestari et al. 2018). Sehingga sangat penting untuk mengetahui dan meneliti tentang keanekaragaman dan hubungan kekerabatan kupu-kupu tersebut yang dilihat dari karakter morfologinya.

Penelitian kupu-kupu

Rhopalocera sudah banyak dilakukan di Indonesia, khususnya di pulau Jawa (Peggie \& Amir 2006; Peggie 2011; Peggie 2014). Namun tidak untuk di Sumatera khususnya Provinsi Riau. Beberapa diantaranya penelitian yang sudah dilakukan di Riau seperti di kawasan Hapanasan Kabupaten Rokan Hulu (Chahyadi \& Bibas 2016), kawasan kampus Universitas Pasir Pangaraian Kabupaten Rokan Hulu (Rodianti et al. 2015), dan kawasan Taman Nasional Bukit Tiga Puluh (Chahyadi et al. 2020). Pada penelitian ini, akan melihat keanekaragaman jenis kupukupu yang berada di kawasan Desa Siabu Salo Kabupaten Kampar dan kawasan hutan yang ada di Universitas Riau. Kemudian membandingkan bagaimana karakter morfologi kupu-kupu dari dua kawasan tersebut. Pemilihan kedua lokasi tersebut dilatar belakangi karena Desa Siabu memiliki habitat yang bervariasi seperti hutan, areal perkebunan karet dan padang rumput. Begitu juga halnya dengan di Universitas Riau yang memiliki kawasan yang bervariasi dan disenangi kupu-kupu seperti ruang terbuka hijau atau arboretum, kebun buah dan taman. Informasi pada penelitian ini diharapkan dapat melengkapi data kupu-kupu Rhopalocera di Provinsi Riau, juga tentunya di Indonesia.

\section{METODE PENELITIAN}

Sampel diambil dari Desa Siabu Kabupaten Kampar dan Kampus Universitas Riau Tampan. Lokasi pengambilan sampel di kawasan Universitas Riau Tampan Pekanbaru dilakukan di Arboretum UNRI (N 00²8'41.6” E 101'22'37.2”), perkebunan FAPERTA (N 00'28'01.3" E 101'22'12.4”), dan Rusunawa UNRI (N 00²7'26.7” E 101'23'30.2”), kemudian lokasi pengambilan sampel di Desa Siabu Kabupaten Kampar dilakukan pada tiga lokasi, yaitu hutan sekunder (N 00'13'09.9” E $\left.101^{\circ} 02^{\prime} 47.2^{\prime \prime}\right)$, perkebunan karet (N 00¹4'34.1" $\mathrm{E}$ $\left.101^{\circ} 01^{\prime} 75.4^{\prime \prime}\right)$, dan pemukiman warga (N 00'13'67.2” E 10100'30.8”). Identifikasi sampel dan analisis data dilakukan di Laboratorium Genetika dan Zoologi Jurusan Biologi FMIPA Universitas Riau.

Koleksi dan pengawetan sampel. Koleksi sampel menggunakan metode eksplorasi dengan menangkap langsung kupu-kupu menggunakan insect net. Waktu koleksi yaitu pukul 08.00 sampai dengan sore hari pukul 17.00 WIB, di koleksi selama tiga hari pada masingmasing kawasan. Pengambilan sampel hanya dilakukan pada hari cerah, karena jika cuaca hujan dan mendung menyebabkan aktifitas kupu-kupu cendrung berkurang, sehingga koleksi tidak optimal (Helmiyetti et al. 2012). Kupu-kupu yang berukuran kecil dikoleksi dengan cara menekan pada bagian toraksnya, sedangkan kupu-kupu yang berukuran besar disuntik pada bagian toraks. Sampel dimasukkan ke dalam kertas papilot yang berbentuk segitiga lalu diberi label nama lokasi, waktu pengambilan, dan nama pengoleksinya. Sampel diawetkan dengan cara membuat insektarium, 
dengan beberapa metode yaitu proses penusukan, pelabelan, pengeringan $\left(45{ }^{0} \mathrm{C}\right)$ dan penyimpanan di dalam kotak koleksi yang sudah diberi kapur barus (Peggie \& Amir (2006; Septianella et al. 2015).

Identifikasi sampel dan analisis data.

Karater bagian tubuh yang diamati sebanyak 25 karakter. Karakter pada bagian kepala yaitu warna dan panjang kepala; warna, panjang, dan bentuk antena; warna probosis; warna dan panjang labial pulp. Karakter pada bagian torkas dan kaki yaitu panjang toraks; warna atas dan bawah toraks; warna kaki; panjang kaki depan, tengah dan belakang. Kemudian karakter pada sayap dan abdomen yaitu warna sayap atas dan bawah; panjang sayap depan dan belakang; lebar sayap depan dan belakang; bentuk tepian sayap; panjang abdomen; warna abdomen atas dan bawah. Identifikasi tersebut merujuk pada sumber Braby (2004), Triplehorn dan Johnson (2005), Peggie \& Amir (2006), Abang (2006), Schulze (2007), dan Ford
(2012). Setelah sampel kupu-kupu diidentifikasi, lalu disajikan secara deskriptif berupa gambar dan tabel.

\section{HASIL DAN PEMBAHASAN}

A. Jumlah individu dan jenis Kupu-kupu (Rhopalocera)

Total kupu-kupu yang diperoleh pada kedua lokasi selama penelitian adalah 363 individu yang terdiri dari 5 famili, 13 subfamili, 32 genus dan 47 jenis. Kupu-kupu yang diperoleh dari kedua lokasi didominasi oleh Famili Nymphalidae sebanyak 231 individu terdiri dari 28 jenis (Tabel 1). Hal ini dikarenakan oleh famili ini merupakan famili terbesar jumlahnya dalam ordo Lepidoptera (Lamatoa et al. 2013). Famili Nymphalidae juga memiliki sebaran yang lebih luas dan tingkat kelimpahan yang lebih tinggi dibanding famili lainnya (Bibas 2016). Jumlah famili Nymphalidae yang tinggi juga didukung oleh ketersediaan pakan yang beragam dan melimpah bagi larva dan kupukupu dewasa (Dewi et al. 2016).

Table 1. Kupu-Kupu yang diperoleh di Universitas Riau Tampan Pekanbaru dan Desa Siabu Kabupaten Kampar Provinsi Riau

\begin{tabular}{|c|c|c|c|c|}
\hline No & Famili & Subfamili & Genus & Spesies \\
\hline 1 & Lycaenidae & Polyommatinae & Catochrysops & Catochrysops amasea \\
\hline 3 & & & Freyeria & Freyeria putli \\
\hline 2 & & & Jamides & Jamides amarauge \\
\hline 4 & & & Nacaduba & Nacaduba berenice \\
\hline 5 & Nymphalidae & Danainae & Euploea & Euploea mulciber \\
\hline 6 & & & & Euploea leucostictos \\
\hline 7 & & & Parantica & Parantica agleoiides \\
\hline 8 & & & Danaus & Danaus genutia \\
\hline 9 & & Heliconiinae & Acraea & Acraea terpsicore \\
\hline 10 & & Argynninae & Cethosia & Cethosia hypsea \\
\hline 11 & & Theclinae & Vindula & Vindula erota \\
\hline 12 & & Satyrinae & Rapala & Rapala varuna \\
\hline 13 & & & Elymnias & Elymnias nesaea \\
\hline 14 & & & Mycalesis & Mycalesis perseus \\
\hline 15 & & & Orsotriena & Orsotriaena medus \\
\hline 16 & & & Ypthima & Ypthima baldus \\
\hline 17 & & & & Ypthima Philomela \\
\hline 18 & & Nymphalinae & Hypolimnas & Hypolimnas alimena \\
\hline 19 & & & & Hypolimnas bolina \\
\hline 20 & & & & Hypolimnas missipus \\
\hline 21 & & & Junonia & Junonia atlites \\
\hline 22 & & & & Junonia hedonia \\
\hline
\end{tabular}




\begin{tabular}{|c|c|c|c|c|}
\hline 23 & & & & Junonia orithya \\
\hline 24 & & & Euthalia & Euthalia aconthea \\
\hline 25 & & & & Euthalia malacana \\
\hline 26 & & & Doleschallia & Doleschallia bisaltide \\
\hline 27 & & Limenitinae & Tanaecia & Tanaecia palguna \\
\hline 28 & & & Neptis & Neptis hylas \\
\hline 29 & & & & Neptis clinioides \\
\hline 30 & & & Athyma & Athyma perius \\
\hline 31 & & Biblidinae & Ariadne & Ariadne ariadne \\
\hline 32 & & & Laringa & Laringa horsfieldi \\
\hline 33 & Pieridae & Coliadinae & Catopsilia & Catopsilia pyranthe \\
\hline 34 & & & & Catosilia scylla \\
\hline 35 & & & & Catopsilia ponoma \\
\hline 36 & & Pierinae & Eurema & Eurema hecabe \\
\hline 37 & & & Appias & Appias ada \\
\hline 38 & & & & Appias olferna \\
\hline 39 & & & Delias & Delias hyparete \\
\hline 40 & & & & Delias crithoe \\
\hline 41 & & & Leptosia & Leptosia nina \\
\hline 42 & Papilionidae & Papilioninae & Papilio & Papilio demoleus \\
\hline 43 & & & & Papilio demolion \\
\hline 44 & & & & Papilio memnon \\
\hline 45 & & & & Papilio polytes \\
\hline $\begin{array}{l}46 \\
47\end{array}$ & Hesperiidae & Hesperiinae & $\begin{array}{l}\text { Ocybadistes } \\
\text { Hesperilla }\end{array}$ & $\begin{array}{l}\text { Ocybadistes walkeri } \\
\text { Hesperilla Sarnia }\end{array}$ \\
\hline
\end{tabular}

\section{B. Deskripsi Morfologi Kupu- Kupu yang diperoleh dari dua kawasan}

Terdapat sebanyak 18 jenis kupu-kupu Rhopalocera yang ada di Universitas Riau Tampan Pekanbaru dan Desa Siabu Kabupaten Kampar. Beberapa jenis kupu-kupu tersebut yaitu Acraea terpsicore, Appias olferna Betina, Appias olferna jantan,
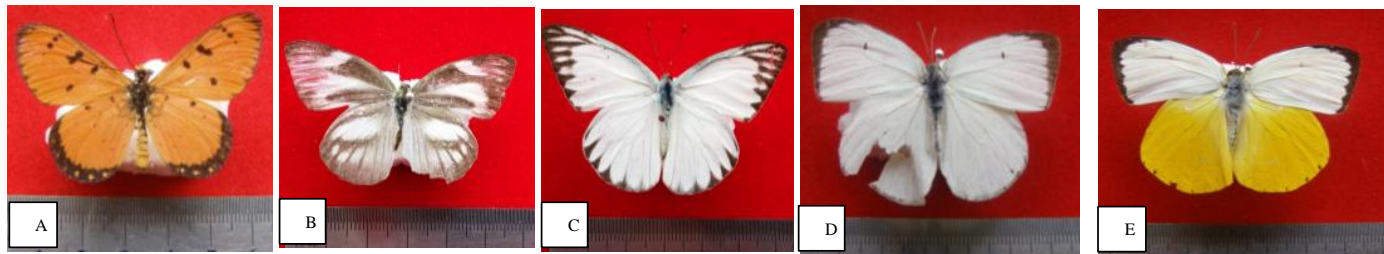
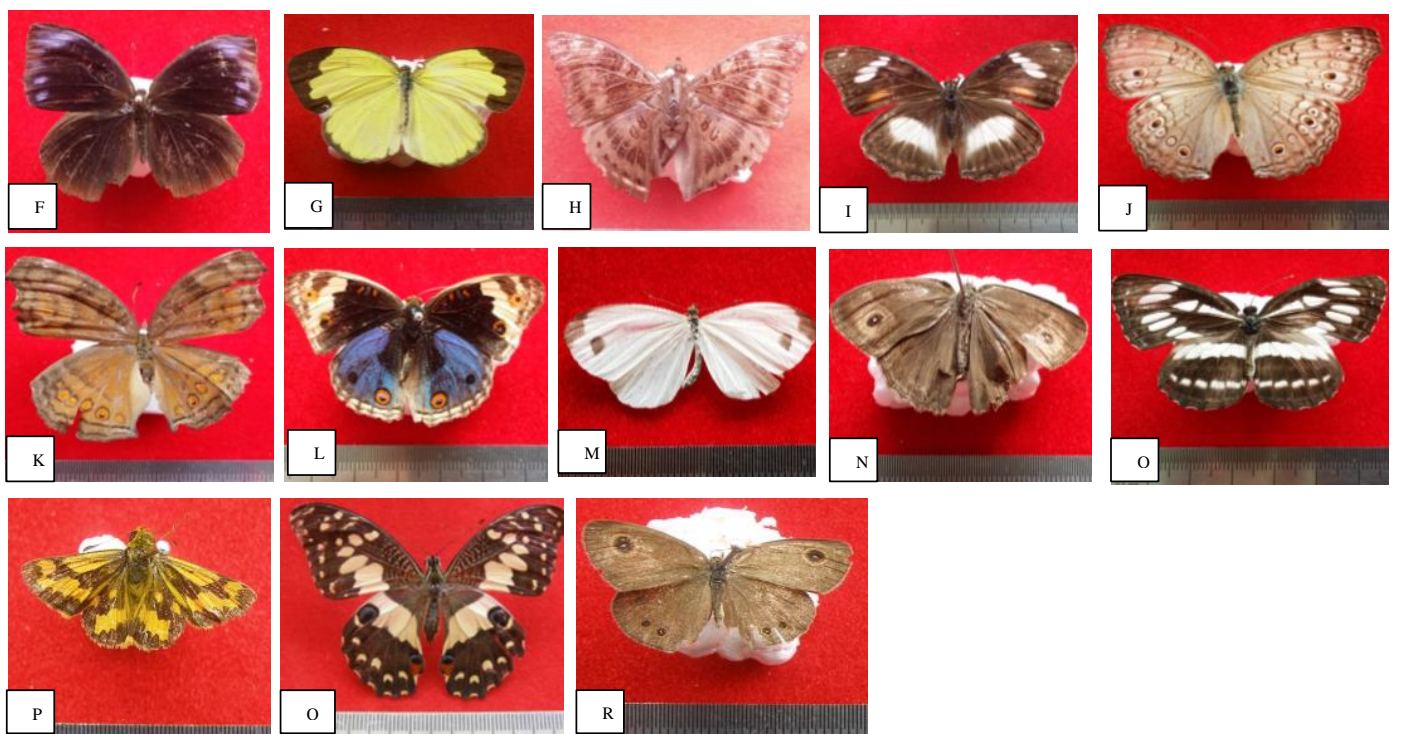

Bio-Lectura: Jurnal Pendidikan Biologi, Vol 8, No 2, Oktober 2021 
Gambar 1. Jenis-jenis kupu-kupu Rhopalocera. $\mathrm{A}=$ Acraea terpsicore, $\mathrm{B}=$ Appias olferna Betina, $\mathrm{C}=$ Appias olferna jantan, $\mathrm{D}=$ Catopsilia pyranthe, $\mathrm{E}=$ Catopsilia scylla jantan, $\mathrm{F}=$ Elymnias nasaea, $\mathrm{G}=$ Eurema hecabe, $\mathrm{H}=$ Euthalia aconthea, $\mathrm{I}=$ Hypolimnas bolina betina, J= Junonia atlites, $\mathrm{K}=$ Junonia hedonia, $\mathrm{L}=$ Junonia orithya jantan, $\mathrm{M}=$ Leptosia nina, $\mathrm{N}=$ _Mycalesis perseus, $\mathrm{O}=$ Neptis hylas, $\mathrm{P}=$ Ocybadistes walker, $\mathrm{Q}=$ Papilio demoleus, $\mathrm{R}=$ Ypthima Philomela

\section{Acraea terpsicore}

\section{Deskripsi:}

Warna kepala hitam (N 0,5) bintik putih (N 9,5), panjang kepala 2-2,1 $\mathrm{mm}$. Warna antena hitam (N 0,5), panjang antena 10,8-11,3 $\mathrm{mm}$ dan bentuk antena ujung membonggol. Warna probosis hitam $(\mathrm{N} 0,5)$, warna labial pulp jingga $(2,5 \mathrm{Y} \quad 8,5 / 8)$, panjang labial pulp 3,1-3,3 $\mathrm{mm}$. Warna toraks atas hitam $(\mathrm{N} 0,5)$ bintik jingga (2,5 Y 8,5/8), warna toraks bawah hitam $(\mathrm{N} 0,5)$ bintik jingga $(2,5 \mathrm{Y}$ 8,5/8), panjang toraks 5-5,1 mm. Warna abdomen atas Jingga (2,5 Y 8,5/8), warna abdomen bawah Jingga (2,5 Y 8,5/8), panjang abdomen 11-11,7 mm. Warna utama sayap atas Jingga (5 YR 7/12), warna utama sayap bawah Jingga $(2,5 \mathrm{Y}$ $8,5 / 8$ ), panjang sayap depan 25,7$28,3 \mathrm{~mm}$, panjang sayap belakang 18,5-19,5 mm, lebar sayap depan 17,4-17,9 mm, lebar sayap belakang 14,4-14,8 mm, bentuk tepian sayap belakang halus, warna kaki jingga (2,5 Y 8,5/8), panjang kaki depan 3,3-3,4 mm, panjang kaki tengah 9,29,3 $\mathrm{mm}$, dan panjang kaki belakang 9,1 mm.

\section{Appias olferna Betina}

Deskripsi:

Warna kepala hitam (N 0,5), panjang kepala $2 \mathrm{~mm}$. Warna antena hitam $(\mathrm{N}$ $0,5)$, panjang antena $10,4-10,5 \mathrm{~mm}$ dan bentuk antena ujung membonggol. Warna probosis cokelat (2,5 YR 7/8), warna labial pulp putih (N 9,5), panjang labial pulp 2,6-3 mm. Warna toraks atas hitam (N 0,5), warna toraks bawah putih (N 9,5), panjang toraks 4,7-5,5 $\mathrm{mm}$. Warna abdomen atas hitam (N $0,5)$, warna abdomen bawah putih $(\mathrm{N}$ 9,5), panjang abdomen 8-8,6 mm. Warna utama sayap atas Cokelat (5YR 3/4), warna utama sayap bawah putih $(\mathrm{N} 9,5)$ dan kuning $(7,5$ Y 8,5/10), panjang sayap 26,4-26,5 mm, panjang sayap belakang 19,8$20,5 \mathrm{~mm}$, lebar sayap depan 16,7$18,5 \mathrm{~mm}$, lebar sayap belakang 17 $17,5 \mathrm{~mm}$, bentuk tepian sayap belakang halus, warna kaki putih $(\mathrm{N}$ 9,5), panjang kaki depan 4,5-5,5 mm, panjang kaki tengah 8,2-11,5 mm, dan panjang kaki belakang 9,1-9,5 mm.

\section{Appias olferna jantan}

Deskripsi:

Warna kepala putih $(\mathrm{N} 9,5)$, panjang kepala 2-2,2 $\mathrm{mm}$. Warna antena hitam (N 0,5), panjang antenna 10,4$11 \mathrm{~mm}$ dan bentuk antena ujung membonggol. Warna probosis cokelat (2,5 YR 7/8), warna labial pulp putih (N 9,5), panjang labial pulp $3 \mathrm{~mm}$. Warna toraks atas hitam $(\mathrm{N} 0,5)$, warna toraks bawah putih $(\mathrm{N}$ 9,5), panjang toraks 5,6-5,8 $\mathrm{mm}$. Warna abdomen atas Hitam ( $\mathrm{N} 0,5)$, warna abdomen bawah putih (N 9,5), panjang abdomen 8,7-11,6 mm. Warna utama sayap atas putih (N $9,5)$, warna utama sayap bawah putih (N 9,5), panjang sayap depan 26$28,9 \mathrm{~mm}$, panjang sayap belakang 17,6-20,7 mm, lebar sayap depan 17,6-18,8 mm lebar sayap belakang 17-19,1 mm, bentuk tepian sayap belakang halus, warna kaki putih $(\mathrm{N}$ 
9,5), panjang kaki depan 4,2-6,6 mm panjang kaki tengah 9,8-11,4 mm, dan panjang kaki belakang 9,7-11,4 $\mathrm{mm}$.

\section{Catopsilia pyranthe}

Deskripsi:

Warna kepala hitam (N 0,5), panjang kepala 2,5-3,2 $\mathrm{mm}$. Warna antena hitam (N 0,5), panjang antena 9-11 $\mathrm{mm}$ dan bentuk antena ujung membonggol. Warna probosis cokelat (2,5 YR 7/8), warna labial pulp putih (N 9,5), panjdWgrihabkepala pulp $3 \mathrm{~mm}$. Warna toraks atas hitam (N 0,5), warna toraks bawah putih $(\mathrm{N}$ 9,5), dan panjang toraks 5,5-7 $\mathrm{mm}$. Warna abdomen atas putih (N 9,5), warna abdomen bawah putih (N 9,5), panjang abdomen 10,2-11 $\mathrm{mm}$. Warna sayap utama sayap atas putih (N 9,5), warna utama sayap bawah hijau (7,5 GY 8/6), panjang sayap depan 29,5-33,5 mm, panjang sayap belakang 22-24,5 $\mathrm{mm}$, lebar sayap depan 17-20 mm, lebar sayap belakang 19-21,2 $\mathrm{mm}$, bentuk tepian sayap bawah halus, warna kaki hijau 7,5 GY 8/6), panjang kaki depan 6,5$8,5 \mathrm{~mm}$, panjang kaki tengah $12-12,2$ $\mathrm{mm}$, dan panjang kaki belakang 10$12,2 \mathrm{~mm}$.

\section{Catopsilia scylla jantan}

Deskripsi:

Warna kepala cokelat (2,5 YR 7/8), panjang kepala $3 \mathrm{~mm}$. Warna antena hitam (N 0,5), panjang antena 11-12 $\mathrm{mm}$ dan bentuk antena ujung membonggol. Warna probosis cokelat (2,5 YR 7/8), warna labial pulp kuning (7,5 Y 8,5/12), panjang labial pulp $3 \mathrm{~mm}$. Warna toraks atas hitam (N 9,5), warna toraks bawah kuning (7,5 Y 8,5/12), panjang toraks $7 \mathrm{~mm}$. Warna abdomen atas

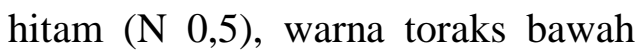
putih (N 9,5), panjang abdomen 9-10 mm. Warna utama sayap atas putih (N 9,5) dan kuning (5 Y 8,5/14), warna utama sayap bawah $(7,5 \mathrm{Y}$ $8,5 / 12$ ), panjang sayap depan 32-33 $\mathrm{mm}$, panjang sayap belakang 22-26 $\mathrm{mm}$, lebar sayap depan 18-20 mm, lebar sayap belakang 22-25 mm, bentuk tepian sayap belakang halus, warna kaki kuning (7,5 Y 8,5/12), panjang kaki depan 10-11 mm, panjang kaki tengah $12-13 \mathrm{~mm}$, dan panjang kaki belakang 10-12 mm.

\section{Elymnias nasaea}

Deskripsi:

cokelat (7,5 YR 3/4), panjang kepala $2 \mathrm{~mm}$. Warna antena cokelat $(2,5$ YR4/8, panjang antena $13-13,3 \mathrm{~mm}$ dan bentuk antena ujung meramping. Warna probosis cokelat (2,5 YR 7/8), warna labial pulp cokelat $(2,5$ YR 7/8), panjang labial pulp $4 \mathrm{~mm}$. Warna toraks atas hitam ( $\mathrm{N} 0,5)$, warna toraks bawah cokelat $(2,5$ YR $8 / 6$ ), panjang toraks $5,5-6,3 \mathrm{~mm}$. Warna abdomen atas cokelat $(7,5$ YR 3/4), warna abdomen bawah cokelat (10 YR 4/6), panjang abdomen 11,8$12,2 \mathrm{~mm}$. Warna utama sayap atas cokelat (7,5 YR 2,5/2), warna utama sayap bawah cokelat (10 YR 4/6), panjang sayap depan 30,3-35,5 mm, panjang sayap belakang 24,8-27,2 mm, lebar sayap depan 20,3-22,5 $\mathrm{mm}$, lebar sayap belakang 20,3-22,2 $\mathrm{mm}$, bentuk tepian sayap belakang bergelombang, warna kaki cokelat (10 YR 4/6), panjang kaki depan 3 $\mathrm{mm}$, panjang kaki tengah, 11,5-12,2 $\mathrm{mm}$, panjang kaki belakang $12 \mathrm{~mm}$.

\section{Eurema hecabe}

Deskripsi:

Warna kepala kuning (10 Y 8,5/12), panjang kepala 1,9-2 $\mathrm{mm}$. Warna antena hitam $(\mathrm{N} 0,5)$, panjang antena 6,6-7,6 $\mathrm{mm}$ dan bentuk antena ujung membonggol. Warna probosis cokelat (2,5 YR 7/8), warna labial pulp kuning (10 Y 8,5/12), panjang labial pulp 1,8-1,7 mm. Warna toraks atas hitam $(\mathrm{N} 0,5)$, warna toraks 
bawah kuning (7,5 Y 8,5/12) panjang toraks 3,8-4,1 mm. Warna abdomen atas hitam $(\mathrm{N} 0,5)$, warna abdomen bawah kuning (10 Y 8,5/12), panjang abdomen 8,1-9,3 mm. Warna utama sayap atas kuning (10 Y 8,5/12), warna utama syap bawah kuning (10 Y 8,5/12), panjang sayap depan 21,1$22,1 \mathrm{~mm}$, panjang sayap belakang 17,7-18 mm, lebar sayap depan 12,213,2 mm, lebar sayap belakang, 15,3$15,7 \mathrm{~mm}$, bentuk tepian sayap belakang halus, warna kaki kuning (7,5 Y 8,5/12), panjang kaki depan 3,4-4,1 mm, panjang kaki tengah 6,67,5 mm, panjang kaki belakang 7,27,5 mm.

\section{Euthalia aconthea}

\section{Deskripsi:}

Warna kepala cokelat (7,5 YR 3/4), panjang kepala 2-3 mm. Warna antena cokelat (2,5 YR 4/8), panjang antena 17-18 $\mathrm{mm}$, bentuk antena ujung membonggol. Warna probosis hijau (2,5 GY 6/10), warna labial pulp cokelat (2,5 YR 7/8), panjang labial $5 \mathrm{~mm}$. Warna toraks atas hitam (10 YR 3/4), warna toraks bawah putih $(\mathrm{N} 9,5)$, panjang toraks $10 \mathrm{~mm}$. Warna abdomen atas hitam ( $\mathrm{N} 0,5)$, warna abdomen bawah putih (N 9,5), panjang abdomen 7-8 mm. Warna utama sayap atas cokelat $(7,5$ YR $5 / 6$ ), warna utama sayap bawah cokelat (10 YR 4/6), panjang sayap depan 28-37 $\mathrm{mm}$, panjang sayap belakang 21-24 mm, lebar sayap depan, 21-26 mm, lebar sayap belakang $22 \mathrm{~mm}$, bentuk tepian sayap belakang halus, warna kaki cokelat (10 YR 4/6), panjang kaki depan 5-6 mm, panjang kaki tengah 15-17 mm, panjang kaki belakang 14-15 mm.

\section{Hypolimnas bolina betina}

Deskripsi:

Warna kepala hitam (N 0,5 ) bintik putih (N 9,5), panjang kepala 2,7-3 mm. Warna antena hitam (N 0,5), panjang antena 14,5-16 $\mathrm{mm}$ dan bentuk antena ujung membonggol. Warna probosis cokelat (2,5 YR 7/8), warna labial pulp cokelat $(2,5$ YR 7/8), panjang labial pulp 4,5-5 $\mathrm{mm}$. Warna toraks atas hitam (10 YR 3/4), warna toraks bawah cokelat $(2,5$ YR $8 / 6)$, panjang toraks $7-8,2 \mathrm{~mm}$. Warna abdomen atas hitam (10 YR $3 / 4$ ), warna abdomen bawah cokelat (2,5 YR8/6), panjang abdomen 12,7$13,2 \mathrm{~mm}$. Warna utama sayap atas cokelat (10 YR 4/6), warna utama sayap bawah cokelat (10 YR 4/6), panjang sayap depan 40,25-42,7 mm, panjang sayap belakang 29-30,7 mm, lebar sayap depan 25,7-28,5 mm, lebar sayap belakang 26-27,5 mm, bentuk tepian sayap bawah bergelombang, warna kaki cokelat (10 YR 4/6), panjang kaki depan 5,7$6 \mathrm{~mm}$, panjang kaki tengah 17-17,7 $\mathrm{mm}$, dan panjang kaki belakang 17,5-17,7 mm.

\section{Junonia atlites}

Deskripsi:

Warna kepala cokelat (2,5 YR 7/8), panjang kepala $2 \mathrm{~mm}$. Warna antena cokelat (2,5 YR 4/8), panjang antena 12-13 mm dan bentuk antena ujung membonggol. Warna probosis putih (10 YR 7/10), warna labial pulp putih (N 9,5), panjang labial pulp 3,2-3,8 mm. Warna toraks atas hitam (N 0,5), warna toraks bawah putih ( $\mathrm{N}$ 9,5), panjang toraks 5-5,7 $\mathrm{mm}$. Warna abdomen atas hitam ( $\mathrm{N} 0,5)$, warna abdomen bawah puih (N 9,5), panjang abdomen $8-10,8 \mathrm{~mm}$. Warna utama sayap atas cokelat (7,5 YR 5/6), warna utama sayap bawah putih (10 YR 7/10), panjang sayap depan 30,5-33 $\mathrm{mm}$, panjang sayap belakang 24,9-26 mm, lebar sayap depan 20,3$21 \mathrm{~mm}$, lebar sayap belakang 22-23 $\mathrm{mm}$, bentuk tepian sayap bawah bergelombang, warna kaki putih (10 
YR 7/10), panjang kaki depan 4,1-5 $\mathrm{mm}$, panjang kaki tengah 12,1-15 $\mathrm{mm}$, dan panjang kaki belakang 12,1-15 mm.

\section{Junonia hedonia}

Deskripsi:

Warna kepala cokelat (2,5 YR 7/8), panjang kepala 2-3 mm. Warna antena cokelat (2,5 YR 4/8), panjang antena $13 \mathrm{~mm}$, bentuk antena ujung membonggol. Warna probosis cokelat (2,5 YR 7/8), warna labial pulp cokelat (2,5 YR 7/8), panjang labial pulp 3-4 $\mathrm{mm}$. Warna toraks atas cokelat (2,5 YR 7/8), warna toraks bawah cokelat (10 YR 4/6), panjang toraks $6 \mathrm{~mm}$. Warna abdomen atas cokelat (10 YR 4/6), warna abdomen bawah cokelat (10 YR 4/6), panjang abdomen 7-8 $\mathrm{mm}$. Warna utama sayap atas cokelat (10 YR 4/6), warna utama sayap bawah cokelat(10 YR 4/6), panjang sayap depan $30 \mathrm{~mm}$, panjang sayap belakang 23-26 mm, lebar sayap depan 19-21 mm, lebar sayap belakang 21-24 mm, bentuk tepian sayap bawah bergelombang, warna kaki cokelat (10 YR 4/6), panjang kaki depan 4-5 mm, panjang kaki tengah $13 \mathrm{~mm}$, dan panjang kaki belakang 13-14 $\mathrm{mm}$.

\section{Junonia orithya jantan}

Deskripsi:

Warna kepala cokelat (2,5 YR 7/8), panjang kepala 2,2-3 $\mathrm{mm}$. Warna antena cokelat (2,5 YR 4/8), panjang antena 11-11,6 $\mathrm{mm}$ dan bentuk antena ujung membonggol. Warna probosis cokelat (2,5 YR 7/8), warna labial pulp cokelat (2,5 YR 7/8), panjang labial pulp 3,4-4 $\mathrm{mm}$. Warna toraks atas hitam $(\mathrm{N} 0,5)$, warna toraks bawah cokelat (2,5 YR 8/6), panjang toraks 6-6,1 $\mathrm{mm}$. Warna abdomen atas hitam (N 0,5), warna abdomen bawah coklat(2,5 YR 8/6), panjang abdomen $8,1-9 \mathrm{~mm}$. Warna utama sayap atas hitam $(\mathrm{N} 0,5)$ dan biru 7,5 PB 4/12), warna utama sayap bawah cokelat (2,5 YR 8/6), panjang sayap depan $23,8-27 \mathrm{~mm}$, panjang sayap belakang 18,8-20 mm, lebar sayap depan 16,4-18 mm, lebar sayap belakang 16,9-17 mm, bentuk tepian sayap belakang bergelombang, warna kaki cokelat (2,5 YR 8/6), panjang kaki depan 3,6-4 mm, panjang kaki tengah 12,6$13 \mathrm{~mm}$, dan panjang kaki belakang 12-12,3 mm.

\section{Leptosia nina}

Deskripsi:

Warna kepala hitam (N 0,5), panjang kepala 1,2-2 $\mathrm{mm}$. Warna antena hitam (N0,5), panjang antena 6,3-7,7 $\mathrm{mm}$ dan bentuk antena ujung meramping. Warna probosis cokelat (2,5 YR 7/8), warna labial pulp putih (N 9,5),

panjang labial 1,5 mm. Warna toraks

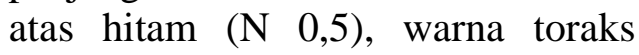
bawah putih (N 9,5), panjang toraks $3 \mathrm{~mm}$. Warna abdomen atas putih ( $\mathrm{N}$ $9,5)$, warna abdomen bawah putih ( $\mathrm{N}$ 9,5), panjang abdomen 8-9,2 $\mathrm{mm}$. Warna utama sayap atas putih(N $9,5)$, warna utama sayap bawah hijau (7,5 GY 8/6), panjang sayap depan 18,3-20 mm, panjang sayap belakang 15,6-16,7 mm, lebar sayap depan 11,5-11,6 mm, lebar sayap belakang 12,3-13,7 mm, bentuk tepian sayap belakang halus, warna kaki hijau $(7,5$ GY 8/6), panjang kaki depan 4,5 $\mathrm{mm}$, panjang kaki tengah 5-7 $\mathrm{mm}$, dan panjang kaki belakang 5-7 $\mathrm{mm}$.

\section{Mycalesis perseus}

Deskripsi:

Warna kepala cokelat (7,5 YR 3/4), panjang kepala $2 \mathrm{~mm}$. Warna antena cokelat (10 YR 4/6), panjang antena 9,5-9,6 $\mathrm{mm}$ dan bentuk antena ujung membonggol. Warna probosis cokelat (2,5 YR 7/8), warna labial pulp (cokelat (10 YR 4/6), panjang 
labial pulp $3 \mathrm{~mm}$. Warna toraks atas cokelat (10 YR 4/4), warna toraks bawah cokelat (10 YR 4/6), panjang toraks 4-4,5 mm. Warna abdomen atas cokelat (2,5 YR 7/8), warna abdomen bawah cokelat (10 YR 4/6), panjang abdomen 9,2-10 $\mathrm{mm}$. Warna utama sayap atas cokelat (10 YR 4/6), warna utama sayap bawah cokelat (10 YR 4/6), panjang sayap depan 22-22,3 $\mathrm{mm}$, panjang sayap belakang 17,5-20,5 $\mathrm{mm}$, lebar sayap depan 14,5-18,3 $\mathrm{mm}$, lebar sayap belakang 15,3-15,5 $\mathrm{mm}$, bentuk tepian sayap belakang halus, warna kaki cokelat (10 YR 4/6), panjang kaki depan 3,5 $\mathrm{mm}$, panjang kaki tengah 8,7-9 $\mathrm{mm}$, dan panjang kaki belakang 9,2-9,5 $\mathrm{mm}$.

\section{Neptis hylas}

\section{Deskripsi:}

Warna kepala cokelat (2,5 YR 7/8), panjang kepala $2 \mathrm{~mm}$. Warna antena cokelat (2,5 YR 7/8), panjang antena 10,3-11,6 $\mathrm{mm}$ dan bentuk antena ujung meramping. Warna probosis cokelat (2,5 YR 8/6), warna labial pulp putih (N 9,5), panjang labial pulp 3,2-3,3 $\mathrm{mm}$. Warna toraks atas hitam (N 0,5), warna toraks bawah putih (N 9,5), panjang toraks 4,1-4,2 $\mathrm{mm}$. Warna abdomen atas hitam $(\mathrm{N}$ $0,5)$, warna abdomen bawah putih $(\mathrm{N}$ 9,5), panjang abdomen 9,5-10,3 mm. Warna utama sayap atas hitam (10 YR 3/4), warna utama sayap bawah cokelat (5 YR 6/12), panjang sayap depan 26,6-27,4 mm, panjang sayap belakang 19,5-19,7 $\mathrm{mm}$, lebar sayap depan 16,6-17 mm, lebar sayap belakang 17,3-17,5 $\mathrm{mm}$, bentuk tepian sayap belakang bergelombang, warna kaki putih $(\mathrm{N}$ 9,5), panjang kaki depan 2,5-2,7 mm, panjang kaki tengah 8,6-10,3 mm, dan warna kaki belakang 9,3-9,5 $\mathrm{mm}$.

\section{Ocybadistes walkeri \\ Deskripsi:}

Warna kepala jingga (10 YR 8/14), panjang kepala 2,2-2,5 mm. Warna antena jingga (2,5 YR 7/12), panjang antena 6-6,5 $\mathrm{mm}$ dan bentuk antena ujung meramping. Warna probosis cokelat (10 YR 3/4), warna labial pulp jingga (2,5 YR 7/12), panjang labial pupl 2-2,2 $\mathrm{mm}$. Warna toraks atas cokelat (10 YR 3/4), warna toraks bawah jingga (7,5 YR 7/12), panjang toraks 4,8-5,5 mm. Warna abdomen atas cokelat (10 YR 4/4), warna abdomen bawah jingga $(7,5$ YR7/12), panjang abdomen 5,6-7 $\mathrm{mm}$. Warna utama sayap atas jingga (7,5 YR7/12), warna utama sayap bawah jingga (7,5 YR7/12), panjang sayap depan 11,6-13 $\mathrm{mm}$, panjang sayap belakang $8 \mathrm{~mm}$, lebar sayap depan 7,4-8 $\mathrm{mm}$, lebar sayap belakang 7-8 $\mathrm{mm}$, bentuk tepian sayap belakang halus, warna kaki jingga (7,5 YR7/12), panjang kaki depan 5,7-6,5 $\mathrm{mm}$, panjang kaki tengah $7,2 \mathrm{~mm}$, dan panjang kaki belakang $7 \mathrm{~mm}$.

\section{Papilio demoleus}

Deskripsi:

Warna kepala cokelat (5 YR 3/4) belang kuning (7,5 Y 8,5/6), panjang kepala 3-3,3 mm. Warna antena hitam (N 0,5), panjang antena 15,5$17 \mathrm{~mm}$ dan bentuk antena ujung membonggol. Warna probosis cokelat (5 YR 3/4), warna labial pulp uning (7,5 Y 8,5/6), panjang labial pupl $2 \mathrm{~mm}$. Warna toraks atas cokelat (5 YR 3/4), warna toraks bawah cokelat (10 YR 4/6), panjang toraks 6,5-7,5 $\mathrm{mm}$. Warna abdomen atas cokelat (10 YR 3/4), warna abdmen bawah kuning (7,5 Y 8,5/6), panjang abdomen 14-15 mm. Warna utama sayap atas cokelat (5 YR 3/4), warna utama sayap bawah cokelat (2,5 YR 8/6), panjang sayap depan 
40-40,5 mm, panjang sayap belakang 29-30,5 mm, lebar sayap depan 21,5$26 \mathrm{~mm}$, lebar sayap belakang 23-24 $\mathrm{mm}$, bentuk tepian sayap belakang bergelombang, warna kaki cokelat (10 YR 4/6), panjang kaki depan 15,5-15,7 $\mathrm{mm}$, panjang kaki tengah $17,7 \mathrm{~mm}$, dan panjang kaki belakang $17,7 \mathrm{~mm}$.

\section{Ypthima philomela}

\section{Deskripsi:}

Warna kepala cokelat (10 YR 4/6), panjang kepala 1-1,2 mm. Warna antena cokelat (10 YR 4/4), panjang antena 5,4-6,6 $\mathrm{mm}$ dan bentuk antena tali. Warna probosis hitam $(\mathrm{N} 0,5)$, warna labial pulp cokelat (10 YR 4/6), panjang labial pupl 2,5-2,6 mm. Warna toraks atas Hitam $(\mathrm{N} 0,5)$, warna toraks bawah cokelat $(7,5$ YR 6/8), panjnag toraks 3-3,2 $\mathrm{mm}$. Warna abdomen atas cokelat (10 YR $3 / 4$ ), warna abdomen bawah cokelat (7,5 YR 6/8), panjang abdomen 6-6,5 $\mathrm{mm}$. Warna utama sayap atas cokelat (10 YR 4/6), warna utama sayap bawah cokelat (7,5 YR 6/8), panjang sayap depan 14,9-15,9 mm, panjang sayap belakang 11,5-12,7 mm, lebar sayap depan 10,1-10,7 mm, lebar sayap belakang 11,1-11,5 mm, bentuk tepian sayap belakang halus, warna kaki cokelat (7,5 YR 6/8), panjang kaki depan 2,3-5 mm, panjang kaki tengah 7-7,3 mm, dan panjang kaki belakang 7,1-7,5 mm.

\section{KESIMPULAN}

Terdapat sebanyak 47 jenis dan 363 individu kupu-kupu yang berhasil di identifikasi dari kawasan Universitas Riau Kota Pekanbaru dan Desa Siabu Kabupaten Kampar Provinsi Riau. Terdapat sebanyak 18 jenis kupu-kupu yang ditemukan pada dua kawasan tersebut. Jumlah jenis dan individu kupu-kupu Rhopalocera didominasi dari Famili
Nymphalidae.

\section{DAFTAR PUSTAKA}

Abang F. 2006. Butterflies of Malaysia Borneo: Sarawak: Lee Miing Press

Bibas E, Muhammad A, Salbiah D. 2016. Keanekaragaman Kupu-Kupu di Kawasan Gunong Bonsu Kabupaten Rokan Hulu, Provinsi Riau. Jurnal Riau Biologi. 1(6): 39-43.

Braby MF. 2004. The Complete Field Guide to Butterflies of Australia.CSIROPublishing. Canberra.

Chahyadi E, Bibas E. 2016. Jenisjenis kupu-kupu (Sub Ordo Rhopalocera) yang terdapat di Kawasan Hapanasan, Kabupaten Rokan Hulu, Provinsi Riau. Jurnal Riau Biologi. 1(2): 50-56.

Chahyadi E, Isda MN, Destiyana A, Fitmawati, Salbiah D. 2020. Morphology characterization of Rhopalocera in two areas of resrosrt Bukit Tiga Puluh National Park Riau Province. Jurnal Biodjati 5(1): 125-137.

Dewi B, Hamidah A, Siburia J. 2016.

Keanekaragaman dan Kelimpahan Jenis KupuKupu (Lepidoptera; Rhopalocera) di sekitar Kampus Pinang Masak Universitas Jambi. Biospecies. 9 (2): 32-38.

Ford T. 2012. Butterflies of Coastal SEQ. Platypus Graphics, Stafford, Brisbane, Qld. Australia.

Helmiyetti, Manaf S, Sinambela KH. 2012. Jenis Jenis Kupu (Butterflies) yang Terdapat di Taman Nasional Kerinci 
Seblat Resor Ketenong Kecamatan Pinang Belapis Kabupaten Lebong Provinsi Bengkulu. Konservati Hayati 8(1): 22-28.

Lamatoa DC, Koneri R, Siahaan R, Maabuat PV. 2013. Populasi Kupu-Kupu (Lepidoptera) di Pulau Mantenage Sulawesi Utara. Jurnal Ilmiah Sains. 13 (1): 53-56.

Lestari VC et al. 2018. Keanekaragaman Jenis Kupu-kupu Familia Nymphalidae dan Pieridae di Kawasan Cirengganis dan Padang Rumput Cikamal Cagar Alam Pananjung Pangandaran. Jurnal Agrikultura 29 (1): 1-8.

Peggie D, Amir M. 2006. Panduan Praktis Кири-Кири di Kebun Raya Bogor. Pusat Penelitian Biologi LIPI. Bogor.

Peggie D. 2014. Diversitas dan Pentingnya Kupu-Kupu Nusa Kambangan (Jawa, Indonesia). Zoo Indonesia. 23(1): 45-55.

Peggie D. 2014. Mengenal KupuKupu . Pandu Aksara Publishing. Bogor.

Putri RE, Mutiara D. 2014. Keanekaragaman KupuKupu di Kecamatan Sukarame Kota Palembang Provinsi Sumatera Selatan. Sainmatika 11 (2):38-42.

Raja RNL. 2012. Studi Keanekaragaman Kupukupu yang terdapat di Kawasan Hutan Aek Nauli Kabupaten Simalungun Sumatera Utara [Skripsi]. Jurusan Biologi Fakultas Matematika dan Ilmu Pengetahuan Alam
Universitas Negeri Medan. Medan.

Rizal S. 2007. Populasi Kupu-kupu di Kawasan Cagar Alam Rimbo Panti dan Kawasan Wisata Lubuk Minturun Sumatera Barat. Mandiri 9 (3): 177-237.

Rodianti et al.2015. Kupu-Kupu (Rhopalocera) di Sekitar Kampus Universitas Pasir Pengaraian Kabupaten Rokan Hulu Provinsi Riau. Jurnal Mahasiswa Prodi Biologi UPP 1(1):1-2

Schulze CH. 2007. Identification Guide for Butterflies of West Java.

http://www.scribd.com/. Accesed date: 26 Februari 2021 .

Septianella et al. 2015. Identifikasi Serangga di Kawasan Industri Pertambangan Kapur Palimanan, Cirebon, Jawa Barat. PROS SEM NAS MASY BIODIV INDON 1 (8): 17901794.

Subahar TS, Yuliana A. 2012. Butterfly Diversity As A Data Base For The Development Plan Of Butterfly Garden At Bosscha Observatory, Lembang, West Java. Biodiversitas 11 (1): 24-28.

Triplehorn CA, Johnson NF. 2005. Borror and Delongs Introduction to The Study of Insects $7^{\text {th }}$ Edition. Thomson Brooks/Cole. United States of America. 